\title{
Clima de escola e estilos educativos familiares e docentes em escola secundária
}

\section{School climate and teachers and educational family styles in secondary school}

\author{
Ângela Maria Pereira Resende \\ ISET
}

\begin{abstract}
Resumo
O objetivo deste estudo é captar a perspetiva dos alunos do secundário relativas ao Clima de Escola e analisar a sua relação com indicadores de socialização familiar e escolar. A amostra é de 465 alunos do ensino secundário. Não se registam relações nem do clima nem dos estilos educativos com o capital escolar familiar. O clima de escola apresenta relações muito significativas com os estilos educativos docentes. Nesta fase do percurso escolar, as diferenças de opinião dos alunos sobre o clima de escola deve ser sobretudo referida às dinâmicas internas da escola.

Palavras chave Alunos, clima de escola, Práticas educativas familiares e Práticas educativas dos professores.
\end{abstract}

\begin{abstract}
The objective of this study is to understand the secondary school students' perspective on the School Climate and to analyse their relationship with indicators of family and school socialization. The sample is 465 secondary school students. There are no relations of climate or educational styles with family school capital. The school climate has very significant relationships with the educational styles of teachers. At this stage of the school journey, the students' differences in opinion about the school climate should be mainly related to the internal dynamics of the school.

Keywords Students, school climate, family educational practices and teachers educational practices.
\end{abstract}

A escola não é uma ilha, estando inserida num contexto que tem a dimensão local e global. A escola é uma organização cujos atores viveram, vivem e vão viver vários processos de socialização ao longo da sua vida e a forma como esses atores da educação são socializados ajuda a compreender as suas atitudes, comportamentos, visões e estratégias.

\section{Socialização dos jovens}

A socialização dos jovens na sociedade atual acontece numa diversidade de espaços, dos quais se destacam o espaço familiar e o escolar. Nestes dois espaços, que são comuns à quase totalidade dos jovens em idade escolar, ocorrem modalidades diversificadas de socialização.

Tendo em conta os paradigmas deterministas e os paradigmas da ação, Alves-Pinto (1995) considera que, para compreender as socializações variadas que ocorrem na escola o segundo paradigma é mais adequado na medida em que na escola todos os seus elementos interagem, com papéis específicos, todos podem ser vistos como atores numa rede de relações, num sistema de interdependência específico e contextualizado. A socialização não é um processo linear mas antes um processo dialético que decorre numa dinâmica de exteriorização, objetivação e interiorização (Berger \& Luckmann, (1966). A socialização é, segundo Percheron, um processo interativo, multidirecional, uma construção lenta e gradual de códigos simbólicos, uma procura de reconhecimento social de pertença e de relação (1993). Daqui decorre que a socialização familiar e escolar não podem ser vistas como processos estanques, estabilizados, conformados pelos normativos mas antes processos em constante reestruturação. Acresce ainda que a expressão de "go-between" usada por Perrenoud chama a atenção para a realidade do jovem que desenvolve as suas estratégias entre as dinâmicas das redes de interação escolar e familiar.

Importante para a compreensão dos processos de socialização é a referência aos agentes da socialização que têm evoluído do predomínio quase exclusivo das instituições clássicas - família e escola - para outros grupos pertencentes a uma sociedade globalizada, obrigando a uma articulação e negociação constantes entre valores e referências institucionais diversos e a experiência do próprio indivíduo (Setton, 2005. 2010). A socialização não ocorre portanto em contextos coerentes, cabendo ao «socializado» articular uma multiplicidade de referenciais simbólicos, o que foi bem traduzido na expressão de «homem plural» de LAHIRE.

A revisão da literatura salienta por um lado a relação entre experiência escolar e origem social e por outro lado relações entre o capital escolar familiar e as práticas educativas familiares. Admitimos que estas relações podem ter especificidades diferentes se focarmos a nossa atenção em alunos com percursos de socialização escolar curta $-1^{\circ} \mathrm{ou} 2^{\circ}$ ciclos - ou de socialização escolar mais longa como é o caso de alunos do secundário. Fundamental para a análise do estudo é ainda a problemática dos estilos educativos de pais e professores, ambos adultos intervenientes de forma relevante no processo de socialização dos jovens deste grupo etário. Para o efeito socorremo-nos da abordagem 
de Baumrind (1991, 2005) reformulada por Alves-Pinto (Teixeira, \& Alves-Pinto, 2016). Consideramos que a explicitação dos estilos educativos pode ser feita por referência à conjugação da intensidade do apoio e do controlo. Chegamos então a quatro estilos: Autoridade Apoiante; Indulgente; Autoritário e Permissivo. Originariamente concebidos para os estilos familiares, eles podem também elucidar a intervenção dos professores. Estes quatro estilos constituem-se elementos relevantes do contexto em que os jovens se vão socializando.

\section{Clima de escola}

O clima organizacional é de grande relevância para se compreender a experiência que professores e alunos fazem na escola.

O clima de escola começou por ser estudado na perspetiva dos professores (Brunet, 1987, 1992; Gaziel 1987; Teixeira 1993, 1995). Só mais tarde o conceito de clima foi utilizado para estudar a perspetiva dos alunos (Janosz, Georges, \& Parent, 1998; Trickett, \& Moos, 2002; Teixeira, 2008).

Janosz, Georges, \& Parent, docentes da universidade de Montréal, referem a importância de se estudar o ambiente socioeducativo da escola, articulando clima escolar, práticas educativas e problemas escolares e sociais, considerando que, desta forma, se poderá ajudar a compreender a interação entre aspetos individuais e sociais (1998) e que é importante considerar a organização escolar e a qualidade do ambiente educativo como objetos específicos da intervenção na escola secundária. É para este nível de ensino que os investigadores constroem o seu instrumento de avaliação de clima. Consideram estes autores que o clima é a dimensão que afeta mais a experiência social e educativa dos alunos e que aquele que se capta através da perceção dos indivíduos permitindo uma medida intersubjetiva do clima. O clima, nesta perspetiva compreende, as dimensões relacionais, educativas, de segurança, de justiça que confluem para o sentido de pertença.

Uma outra escala, que foi concebida na universidade Standford, refere-se ao clima específico da sala de aula (Trickett \& Moos 2002) e é composta por nove subescalas agrupadas em três conjuntos: dimensões relacionais; dimensões de crescimento pessoal e dimensões de manutenção / mudança de sistema. Mais do que clima de escola, trata-se de clima da sala de aula. $\mathrm{O}$ autor prevê que a aplicação da Escala seja feita de forma tripartida ao criar três tipos de questionário: um "questionário real", que avalia as perceções dos alunos e dos professores relativamente ao seu ambiente real de sala de aula; um "questionário ideal", que mede as conceções dos alunos e dos professores de um ambiente ideal de aprendizagem na sala de aula, e, finalmente, um "questionário de expectativas", que permite medir, como o próprio nome indica, as expectativas de alunos e professores quanto ao ambiente de aprendizagem na sala de aula. As perguntas de cada um dos questionários são iguais, exceto no tempo verbal: enquanto o questionário real usa o presente do indicativo, o questionário ideal e de expectativas usa o tempo futuro.
Enquanto o questionário real permite avaliar o ambiente atual da sala de aula, ajudando tanto alunos como professores a descrevê-lo, o questionário ideal permite a descrição do ambiente de sala de aula que tanto professores como alunos preferem.

M. TEIXEIRA iniciou os seus estudos sobre o clima no início da década de 90 na perspetiva dos professores (Teixeira, 1993, 1995) com um instrumento concebido expressamente para a realidade das escolas portuguesas. Posteriormente alargou as suas análises ao clima de escola visto pelos alunos (Teixeira, 2008). Mais recentemente concluiu por relações muito fortes entre o clima de escola, o sentido de pertença, comportamentos de cidadania e de liderança dos jovens (2014, 2015 e 2016). As dimensões que considera nas investigações mais recentes são: Relação entre atores; Apoio recebido nas dificuldades; Segurança e Tranquilidade na escola e Condições de Trabalho.

As conclusões destes estudos e dos que recorreram aos mesmos instrumentos chegaram à constatação de que o clima de escola exerce forte influência sobre a motivação, a satisfação e o stress tendo consequências ao nível da participação na escola; na adaptação dos alunos à escola; nas aprendizagens escolares, nos resultados escolares, no conceito e confiança que os alunos têm de si; na própria saúde dos alunos e ainda na participação nas atividades escolares assumidas pelos professores.

\section{Metodologia}

\section{Objeto de estudo}

O objetivo deste estudo é conhecer as perspetivas dos alunos do ensino secundário relativas ao Clima de Escola e analisar a sua relação com indicadores de socialização familiar e de socialização escolar.

\section{Instrumento de recolha de dados}

O questionário que utilizámos, para além de perguntas de caracterização, integra indicadores de clima escolar, de socialização familiar, em particular de estilos educativos parentais e de socialização escolar, nomeadamente de estilo educativo docente.

\section{Amostra}

A amostra é constituída por 465 alunos do ensino secundário de uma escola do grande Porto, com uma maioria de alunos a frequentar cursos profissionais. $\mathrm{O}$ método é quantitativo. Os alunos da amostra distribuem-se pelos 3 anos do secundário: $31 \%$ são do $10^{\circ}$ ano, $32 \%$ do $11^{\circ}$ ano e $37 \%$ do $12^{\circ}$ ano. Por tipo de curso $39 \%$ frequentam as áreas do ensino científicohumanístico e $61 \%$ cursos profissionais. Cerca de $1 / 3$ dos alunos já foram retidos no seu percurso escolar. Calculado o nível de instrução parental, como o nível de estudos mais elevado entre o pai e a mãe, encontrámos a seguinte distribuição: $4^{\circ}$ ano $11,7 \% ; 6^{\circ}$ ano $31,2 \% ; 9^{\circ}$ ano $25,8 \%$; Secundário $20,8 \%$ e Curso superior $10,4 \%$. Verificamos assim que só $31 \%$ dos alunos frequentam um nível de estudos já frequentado por, pelo menos um dos seus pais, o que não é indiferente para o apoio que 
possam ter em casa para a descodificação das normas e para a tomada de decisões.

\section{Análise de dados}

Clima de escola: $O$ instrumento do clima de escola, com 34 itens, foi retirado, quase integralmente, de Teixeira (2014), com a forma de escala de Likert, que vai da concordância total à discordância total. Este questionário integra indicadores de quatro grandes dimensões: as dimensões das relações entre atores, do apoio, da segurança e das condições de trabalho. No âmbito deste artigo iremos restringir-nos às dimensões, mas enunciamos as subdimensões para que o leitor tenha uma ideia mais próxima do conteúdo destes indicadores.

Tabela 1.

Clima de escola: dimensões e subdimensões

\begin{tabular}{|c|c|}
\hline Dimensões & Subdimensões \\
\hline \multirow{5}{*}{ Relações entre atores } & Entre colegas \\
\hline & Entre alunos e Direção \\
\hline & Entre alunos e funcionários \\
\hline & Entre alunos e professores \\
\hline & Entre a escola e os pais \\
\hline \multirow{3}{*}{$\begin{array}{l}\text { Apoio recebido nas } \\
\text { dificuldades }\end{array}$} & Apoio dos colegas \\
\hline & O apoio dos professores \\
\hline & O apoio do D.T. /D.C. \\
\hline \multirow{4}{*}{$\begin{array}{c}\text { Segurança e Tranquilidade } \\
\text { na escola }\end{array}$} & Disciplina geral da escola \\
\hline & $\mathrm{Na}$ escola \\
\hline & Nas aulas. \\
\hline & Nos recreios. \\
\hline \multirow{5}{*}{ Condições de Trabalho } & As instalações escolares \\
\hline & Equipamento didático \\
\hline & Horário da escola \\
\hline & T.P.C.s \\
\hline & Atividades extra-curriculares \\
\hline
\end{tabular}

Começaremos por apresentar o gráfico das distribuições destes indicadores construídos a partir das diferentes dimensões mencionadas.

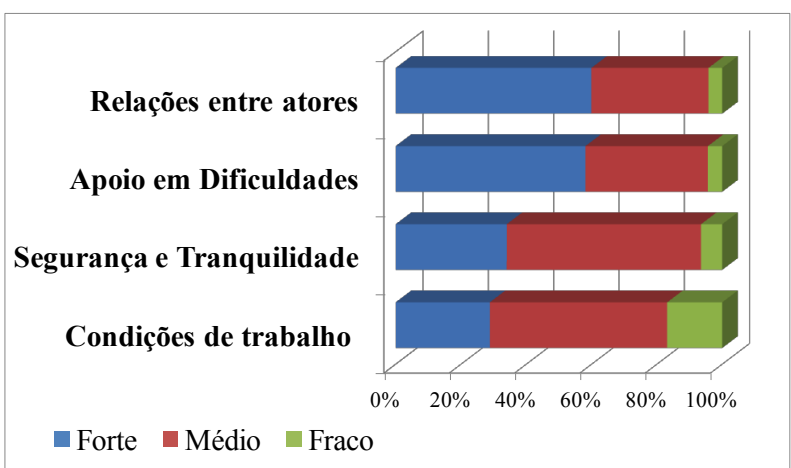

Figura 1: Clima de escola: distribuição das dimensões

A relação entre atores e o apoio recebido em situações sentidas como de dificuldade são as dimensões que tiverem repostas mais favoráveis. Este resultado vai no mesmo sentido das conclusões de Duru-Bellat, Mons, \& Bydanova (2008) na análise que fazem sobre o apoio dado aos alunos pelos professores, nos dados do Pisa. Já a segurança e tranquilidade e particularmente as condições de trabalhos são as dimensões com respostas menos favoráveis.

Estilos Educativos: construímos indicadores de estilos educativos, seguindo a proposta de Alves-Pinto, conjugando a exigência e o apoio. Recolhemos opiniões sobre a exigência dos pais e o apoio dos pais. A partir das respostas a estes dois indicadores construímos o indicador do estilo educativo familiar. Com uma lógica semelhante formulámos questões sobre o que os alunos pensam relativamente à exigência e ao apoio dos professores, para construir um indicador do estilo educativo docente. Chegamos então a quatro tipos educativos:

Autoridade apoiante: Exigência forte e Apoio forte

Indulgente Exigência fraca e Apoio forte

Autoritário: Exigência forte e Apoio fraco

Negligente: Exigência fraca e Apoio fraco

Apresentamos sinteticamente na figura 2 os valores obtidos para os estilos educativos familiares (F) e para os estilos educativos docentes (D).

\section{Estilos Educativos Docente e Familiar}

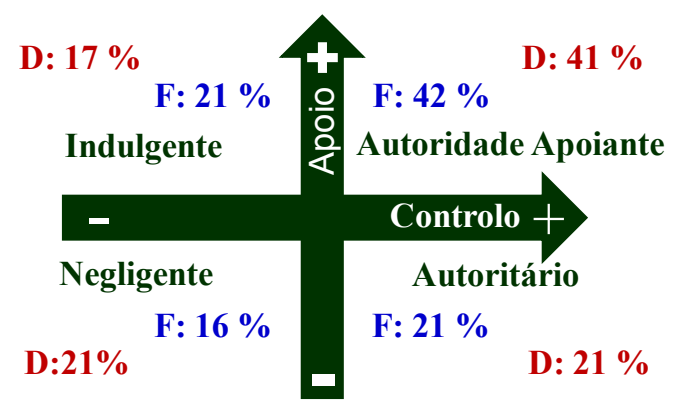

Figura 2: Estilos educativos Familiar (F) e Docente (D)

Constatamos que, na perspetiva dos jovens da nossa amostra, o estilo mais frequente quer entre os docentes quer na família é a autoridade apoiante. Na família em segundo lugar vêm os estilos indulgente e autoritário e em último lugar o negligente. Já quando se trata dos estilos dos professores, os estilos autoritário e negligente vêm em $2^{\circ}$ lugar e o indulgente em último.

Tendo em conta o capital escolar familiar da nossa amostra, interrogamo-nos se o estilo educativo familiar apresenta relação estatisticamente significativa com o nível de instrução familiar. Complementarmente interrogamo-nos se o estilo educativo docente apresenta relação quer com o capital escolar familiar e o estilo educativo familiar.

Calculadas as tabelas de contingência, verificamos que não existe relação estatisticamente significativa do estilo educativo familiar com o nif $\left(\chi^{2}=8,3\right.$; g.l. $=6$; $\mathrm{p}=.218)$.

$\mathrm{O}$ estilo educativo docente por sua vez também não varia com o n.i.f. $\left(\chi^{2}=1,6 ;\right.$ g.l. $\left.=6 ; p=.951\right)$. Mas varia muito fortemente com o estilo educativo familiar (tabela 2).

Os jovens que em casa experimentam um estilo de autoridade apoiante, reconhecem mais frequentemente 
do que os outros que o estilo docente é do mesmo tipo. No outro extremo os jovens que experimentam estilos parental negligente olham mais do que os seus colegas para a estilo educativo dos professores como negligente.

Tabela 2.

Estilo Educativo Docente segundo o Estilo Educativo Familiar

\begin{tabular}{|c|c|c|c|c|c|}
\hline $\begin{array}{l}\text { Estilos } \\
\text { Parentais } \\
\text { Estilos } \\
\text { Docentes }\end{array}$ & 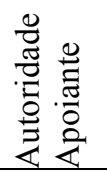 & 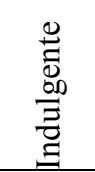 & : & 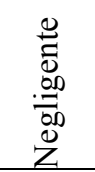 & 吾 \\
\hline $\begin{array}{l}\text { Autoridade } \\
\text { Apoiante }\end{array}$ & $51 \%$ & $37 \%$ & $42 \%$ & $20 \%$ & $41 \%$ \\
\hline Indulgente & $11 \%$ & $23 \%$ & $19 \%$ & $23 \%$ & $17 \%$ \\
\hline Autoritário & $22 \%$ & $18 \%$ & $24 \%$ & $17 \%$ & $21 \%$ \\
\hline Negligente & $15 \%$ & $22 \%$ & $15 \%$ & $40 \%$ & $21 \%$ \\
\hline Total & $100 \%$ & $100 \%$ & $100 \%$ & $100 \%$ & $100 \%$ \\
\hline
\end{tabular}

Uma interpretação possível é que o estilo de autoridade apoiante dê aos jovens mais competências em termos de inteligência emocional de modo a aproveitar as oportunidades relacionais e de contexto da realidade escolar com que se confronta. Estudos posteriores poderão testar se esta interpretação se confirma.

Clima e socialização familiar: Procurámos analisar eventuais relações entre os indicadores de clima e indicadores de socialização familiar. Considerámos não só o estilo educativo familiar como o nível de instrução familiar, dada a relevância do capital escolar da família em muita da literatura da especialidade.

Tabela 3.

$P$ das tabelas de contingência do Clima com indicadores de socialização familiar

\begin{tabular}{lcc}
\hline & \multicolumn{3}{c}{ P - Significância do $\chi^{2}$} \\
\hline & $\begin{array}{c}\text { N.I. } \\
\text { Familiar }\end{array}$ & $\begin{array}{c}\text { Estilo Educativo } \\
\text { Parental }\end{array}$ \\
\hline Clima Relacional & - & $*$ \\
Apoio recebido & - & $*$ \\
Segurança & - & - \\
Condições Trabalho & - & - \\
\hline \multicolumn{4}{c}{$(-) \mathrm{p}>.05$} & $(*) \mathrm{p}<.05$
\end{tabular}

Constatamos que nenhuma das dimensões do clima de escola apresenta variações estatisticamente significativas com o nível de instrução familiar. Já com o estilo educativo familiar registam-se variações com o clima relacional e com o apoio recebido quando têm dificuldades. E as variações registadas são no mesmo sentido. As respostas mais favoráveis para estas duas dimensões registam-se para o estilo da autoridade apoiante, seguido do indulgente. As respostas menos favoráveis são no grupo do estilo negligente e do autoritário.
Clima e socialização escolar: Iremos considerar, nesta análise 3 indicadores: o ano em que está inscrito, o tipo de curso frequentado e o estilo educativo docente. Admitimos que o ano e o tipo de curso frequentado podem interferir na perceção que os alunos têm do clima escolar. Para muitos alunos a transição do $9^{\circ}$ ano para o $10^{\circ}$ ano corresponde a uma grande alteração nas exigências escolares. Acresce, que também para muitos, esta transição supõe o ingresso numa nova escola. Admitimos pois que poderiam existir diferenças, nomeadamente estre os alunos do $10^{\circ}$ ano e os dos anos seguintes. A opção entre curso profissional e curso científico-humanístico pode também corresponder a grupos de alunos com representações específicas sobre o clima de escola. O estilo educativo docente é o terceiro indicador de socialização que iremos utilizar nesta análise. (Tabela 2)

$\mathrm{O}$ ano não apresenta nenhuma variação com clima de escola. Inversamente a opinião dos alunos sobre o apoio recebido, a segurança e as condições variam, a uma aproximação de .05, com o tipo de curso frequentado, sendo os alunos dos cursos científico- humanísticos que manifestam melhores opiniões sobre o clima de escola.

Tabela 4.

$P$ das tabelas de contingência do Clima com indicadores de socialização escolar

\begin{tabular}{|c|c|c|c|}
\hline & \multicolumn{3}{|c|}{ P - Significância do $\chi^{2}$} \\
\hline & Ano & $\begin{array}{c}\text { Tipo de } \\
\text { Curso }\end{array}$ & $\begin{array}{c}\text { Estilo } \\
\text { Educativo } \\
\text { Docente }\end{array}$ \\
\hline Clima Relacional & - & - & $* * *$ \\
\hline Apoio & - & $*$ & $* * *$ \\
\hline Segurança & - & $*$ & $* * *$ \\
\hline Condições Trabalho & - & $* *$ & $* * *$ \\
\hline
\end{tabular}

Mas as relações mais intensas, de todas as dimensões do clima, são as verificadas com as práticas educativas docentes. E analisando as tabelas de contingência encontramos, para as quatro dimensões, as mesmas tendências: as respostas mais favoráveis são as dos jovens que veem estilo educativo docente como de autoridade apoiante, seguido de relativamente perto dos que sentem o estilo indulgente. Na penúltima posição surge $\mathrm{o}$ estilo autoritário $\mathrm{e}$ por último o estilo negligente.

\section{Conclusão}

Concluímos por um lado que, ao nível do secundário, nesta amostra, não se regista relações estatisticamente significativas entre as práticas educativas familiares e o capital escolar; por outro lado não encontrámos relação estatisticamente significativa das dimensões do clima escolar com o capital escolar dos pais. Registamos somente variações do clima relacional e de apoio com os estilos educativos familiares. A opinião mais positiva sobre as relações entre atores e do apoio na escola regista-se nos jovens que experimentam um estilo 
educativo parental do tipo de autoridade apoiante seguido do indulgente. As perspetivas dos jovens sobre o clima de escola não variam com o maior ou menor avanço no percurso escolar. Já o tipo de curso frequentado mostra diferenças, particularmente fortes para as condições de trabalho, com opiniões menos positivas no grupo dos alunos que optaram pelos cursos profissionais. Eventualmente a maior exigência em equipamento especializado assim como os horários mais carregados poderão ajudar a dar conta, pelo menos em parte, deste resultado. Todas as dimensões do clima estão fortemente relacionadas com os indicadores de estilos educativos docentes salientando-se claramente o estilo de autoridade apoiante como o mais promotor de uma representação positiva do clima escolar.

Concluímos assim que nesta fase do percurso escolar, as diferenças de opinião dos alunos sobre o clima de escola deve ser sobretudo referida às dinâmicas internas da escola. Estes dados deverão incentivar a um diálogo entre professores e pais no sentido de promover atitudes conducentes ao reforço do estilo de autoridade apoiante.

\section{Bibliografia}

Alves-Pinto, C. (2008). Da complexidade da socialização escolar. In M. C. Alves-Pinto (Ed.), Alunos na escola - imagens e interações (pp. 19-78). Porto: ISET.

Barros de Oliveira, J. H. (1996). Educação dos adultos-Pais - Estilos educativos parentais. Paper presented at the Educação de adultos em Portugal Situação e perspectivas, Coimbra.

Barros de Oliveira, J. H. (1996). Educação dos adultos-Pais - Estilos educativos parentais Educação de adultos em Portugal - Situação e perspectivas (pp. 307-320). Coimbra: Universidade de Coimbra.

Baumrind, D. (1991). The Influence of Parenting Style on Adolescent Competence and Substance Use. The Journal of Early Adolescence, 11(1), 56-95.

Baumrind, D. (2005). Patterns of Parental Authority and Adolescent Autonomy. New Directions for Child and Adolescent Development, 108(summer), 61-68.

Berger, P., \& Luckmann, T. (1966). A construção social da realidade. Petrópolis: Vozes editora.

Borges, P. A., \& Alves-Pinto, C. (2016). Envolvimento dos alunos e tonalidades de interação: a visão de jovens dos $2^{\circ}, 3^{\circ}$ ciclos e ensino secundário. In $\mathrm{F}$. Veiga (Ed.), Envolvimento dos Alunos na Escola: Perspetivas da Psicologia e Educação - Motivação para o Desempenho Académico (pp. 122-138). Lisboa: IE-UL.

Brunet, L. (1987). Le climat organisationnel et le milieu scolaire. In C. Barnabé \& H. Girard (Eds.), L'administrateur scolaire: théorie et pratique (pp. 241-252). Chicoutimi: Gaëtan Morin Éditeur.

Brunet, L. (1992). Clima de trabalho e eficacia da escola. In A. Nóvoa (Ed.), As organizacoes escolares em analise (pp. 121-139). Lisboa: Dom Quixote.

Duru-Bellat, M., Mons, N., \& Bydanova, E. (2008). Cohésion scolaire et politiques éducatives. Revue française de pédagogie, 164, (julho-setembro), 37-54., 164, 37-54.
Gaziel, H. H. (1987). Climat psychosocial de l'ecole et la satisfaction que les enseignants du second degre tirent de leur travail. Le travail Humain, 50(1), 35-45.

Janosz, M., Georges, P., \& Parent., S. (1998). L'environnement socioéducatif à l'école secondaire : un modèle théorique pour guider l'évaluation du milieu. Revue Canadienne de Psychoéducation, 27(2), 285-306.

Percheron, A. (1993). La socialisation politique. Paris: Colin.

Perrenoud, P. (1995). Ofício de aluno e sentido do trabalho escola. Porto: Porto Editora.

Setton, M. d. G. J. (2005). A particularidade do processo de socialização contemporâneo. Tempo social, 17, 335-350.

Setton, M. d. G. J. (2010). Processos de socialização, práticas de cultura e legitimidade cultural. Estudos de Sociologia, Araraquara, 15(28), 19-35.

Teixeira, M. (2008). Clima de escola - Perspetiva dos alunos. In C. Alves-Pinto (Ed.), Alunos na escola Imagens e Interações (pp. 79-116). Porto: ISET.

Teixeira, M. (2014). Olhares dos alunos sobre a escola: Clima e sentido de Pertença. In F. H. Veiga (Ed.), Envolvimento dos Alunos na Escola: Perspetivas Internacionais da Psicologia e Educação. (pp. 266-278). Lisboa: IE-U.Lisboa.

Teixeira, M., \& Alves-Pinto, C. (2015). School Climate and citizenship: The Portuguese pupils' overview. Journal of Educational, Cultural and Psychological Studies (ECPS)(11), 153-175.

Teixeira, M., \& Alves-Pinto, C. (2016). Liderança dos alunos, clima de escola e estilos educativos docentes: Olhares de alunos dos $3^{\circ}$ ciclo e secundário. In F. H. Veiga (Ed.), Envolvimento dos Alunos na Escola: Perspetivas da Psicologia e Educação - Motivação para o Desempenho Académico (pp. 187-202). Lisboa: Lisboa: IE-U.Lisboa..

Trickett, E. J., \& Moos, R. H. (2002). Classroom Enviroment scale, a social climate scale - Third Edition. Palo Alto: Stanford University Medical Centers. 